RESEARCH ARTICLE

\title{
Molecular Modeling and Dynamics Studies of Hexanal Release from Polyvinyl alcohol - Cyclodextrin Nano-fiber Composite for Extending Shelf-life of Mango
}

\author{
Krithika V. Palanisamy ${ }^{1}$, Jeya Sundara Sharmila $D^{1}$ and Kizhaeral S. Subramanian*1 \\ ${ }^{1}$ Department of Nano Science \& Technology, Tamil Nadu Agricultural University, Coimbatore - 641003
}

\begin{abstract}
Postharvest losses are huge in fruits that can be reduced by exposing them to a biomolecule hexanal, which is known to alter the physiological changes resulting in an extension of shelf-life. Hexanal is a highly volatile compound, it is naturally produced by plants. Its external application extends shelf-life of fruits during storage by inhibiting phospholipase -D enzyme in the cell wall. A study was undertaken to examine the kinetics of hexanal release from the polyvinyl alcohol - $\beta$ cyclodextrin encapsulated nanofiber composite using a molecular modeling approach. The present study focussed on the analysis of the influence of relative humidity and temperature on the nanofiber composite to release hexanal. The release and retention behavior of hexanal was investigated with the relative humidity range of $50 \%-95 \%$ at $27^{\circ} \mathrm{C}$ and $33^{\circ} \mathrm{C}$. The molecular modeling studies have confirmed that the hexanal vapor release is altered with humidity and temperature regimes. This can be used for the fabrication of a delivery system for hexanal in extending the shelf-life of fruits in storage godowns.
\end{abstract}

Received : $14^{\text {th }}$ May, 2020

Revised : $02^{\text {nd }}$ June, 2020

Accepted : $25^{\text {th }}$ June, 2020

Keywords: Polymer; Molecular Modeling, Polyvinyl alcohol; Cyclodextrin; Hexanal; Release Kinetics

\section{INTRODUCTION}

Despite India's statistics is very attractive in the production of many of the fruits, the per capita availability is deficit by $40 \%$ due to the postharvest loss. Postharvest food loss is defined as measurable qualitative and quantitative food loss along the supply chain, starting at the time of harvest until its consumption or other end uses (Hodges et al., 2011). The biggest problem affecting the country's agriculture and the agricultural market is postharvest losses, and it adversely affects the Indian economy. These are due to poor infrastructure and transportation, insufficient or unavailability of cold storages in immediacy to farms, etc., which cause price fluctuations resulting in farmer's frustrations of not getting remunerative prices besides rural economic failure (Ali, 2003; Maheshwar and Chanakwa, 2006; Rolle, 2006). Hence, minimizing the loss can increase the supply without bringing additional land under cultivation. These situations demand strategies to minimize postharvest losses and maximize the availability of fruits.

Electrospinning is a versatile technique for producing multifunctional nanofibers from various polymers, polymer blends, and composites(Greiner and Wendorff, 2007; Li and Xia, 2004). Polyvinyl alcohol (PVA) is used in food technology, pharmaceutical, and biomedical applications for controlled drug release with an added advantage of biodegradability and non-toxic properties (Reis et al., 2006). In the past few years, hexanal based formulations have been found very effective in fruit preservation. Hexanal, a naturally occurring volatile compound, is a potent inhibitor of Phospholipase $D$ activity on the fruit skin. Hexanal is found in nearly 300 natural sources including apple, berries, apricot, banana, guava, sweet and sour cherries, citrus peel oil and juices, etc. with molecular formula $\mathrm{C}_{6} \mathrm{H}_{12} \mathrm{O}$ and molecular mass 100.1 a.m.u, present in a liquid state at Normal Temperature and Pressure (NTP). But hexanal has very low vapor pressure i.e. $10 \mathrm{mmHg}$ at $20^{\circ} \mathrm{C}$, and thus easily volatilized when the temperature rises. Exogenous application of hexanal treatment showed encouraging results in enhancing shelf-life of several fruits such as apple, banana, cherry, peach, strawberry as well as vegetables such as broccoli, tomato, and several fresh-cut vegetables, and flowers such as carnation and rose (Paliyath et al., 1999).

Several novel methods have been used to control postharvest losses. Some of them are viz., use of hot 
water with fungicides to reduce postharvest losses caused by fungal diseases (Iram and Ahmad, 2013), dynamic controlled atmosphere (Kader, 2003), ethylene inhibition technology (Lurie and Paliyath, 2009) and hexanal technology for extended shelflife (Anusuya et al., 2016; Jincy et al., 2017). Many researchers are interested in $\beta$ cyclodextrin ( $\beta-C D)$ nanofiber because it can dramatically improve desirable properties by an increase of the specific surface area. A study reported that incorporating cyclodextrin inclusion complex in electrospun nanofiber have high thermal stability and durability, thus finding application in functional food packaging and preservation (Kayaci et al., 2014).

Up to date, some studies focussed on the morphology improvement of electrospinning nanofibers, but very few researchers take into account the ability of composite nanofibers for capturing guest molecules. To gain further knowledge and precisely to predict the release kinetics, molecular modeling approach was attempted. In recent times, molecular modeling methods have found a wide range of applications in diverse fields and are used to investigate the structure and behavior properties of many polymeric and biological systems. It comprises computational methods and simulations which configures and studies how all molecules behave, ranging from small chemical systems to large molecules and material assemblies. Atomistic modeling is the most common feature and a powerful tool that helps in studying the structural properties of polymer composites (Radosinski and Labus, 2017). Modeling helps in simulating the behavior of a system and provides complete structure and intermolecular interactions (Wu, 2010). Hexanal is entrapped in $\beta$ cyclodextrin and PVA and used as a composite to enhance the shelf-life of fruits. With this view, the present research focuses on molecular modeling of hexanal vaporization, where it is entrapped in PVA and cyclodextrin nanofibers in temperature and relative humidity $(\mathrm{RH})$ regimes. PVA- $\beta$ Cyclodextrin serves as a template to develop nanofiber composite, which effectively entraps hexanal vapor and regulates its release for an extended period of fruits. Such a process enables the extension of shelf-life of mango fruits under storage conditions.

\section{MATERIAL AND METHODS}

\section{Structure generation}

Schrodinger materials science suite (v.2017-3) was used to study the molecular dynamics (MD) and simulation of the nanofiber composites. A primary system was built for PVA- $\beta$ cyclodextrin and hexanal. The structure of hexanal (PubChem CID: 6184) and $\beta$ cyclodextrin (PubChem CID: 444041) were retrieved from the PubChem database (https://pubchem.ncbi.nlm.nih.gov/). Polymer builder panel was used to generate an initial PVA structure (1750 monomers). The numbers of molecules were calculated based on mass percentage. Thirty-four molecules of $\beta$ cyclodextrin and 51 molecules of hexanal were packed in 1 PVA polymer chain containing 438 monomers. The structures were built in a periodic boundary cell of size - 45×51×52 $\AA^{3}$, and the molecular dynamics studies were carried.

\section{Molecular dynamics and minimization}

The molecular dynamics of hexanal release from the nanofiber composite was carried out simulating the experimental parameters such as relative humidity in fruit box i.e., [50 \% to $95 \%$ ] and tropical mango harvesting temperatures $27^{\circ} \mathrm{C}$ (300 Kelvin $(\mathrm{K}))$ and $33^{\circ} \mathrm{C}(303 \mathrm{Kelvin}(\mathrm{K}))$ corresponds to the offseason and regular season of mango, respectively. The MD simulation was carried out for 5 ns duration at $27^{\circ} \mathrm{C}$ (system I) and extended up to $10 \mathrm{~ns}$ period at $33^{\circ} \mathrm{C}$ (system II). The recording interval for the trajectory generation was set as 5 picoseconds (ps). The approximate number of frames was set to 1000 . The pressure was set to 1.01325 bars, and the time step was 2.0 femtosecond (fs). The simulations were run under NPT type, which consists of a constant number of atoms, constant pressure, and constant temperature. OPLS3 (Optimized Potentials for Liquid Simulations) force field was selected for the energy minimization option. The Energy plot (simulation quality analysis) and movement of hexanal release (RMSD) (simulation event analysis) were plotted for the trajectory data obtained for PVA- $\beta$ cyclodextrinhexanal complex at $27^{\circ} \mathrm{C}$ and $33^{\circ} \mathrm{C}$ that were recorded through $\mathrm{MD}$ simulations.

\section{Simulation analysis}

The Energy plot (simulation quality analysis), root mean square deviation (simulation event analysis) were plotted for the trajectory data obtained for PVA- $\beta$ cyclodextrin- hexanal and water complex at $27^{\circ} \mathrm{C}$ and $33^{\circ} \mathrm{C}$ that were recorded through MD simulations.

\section{Modeling the polymer chain backbone}

To confirm the conformation of the PolyVinyl Alcohol chain in the complex, the torsion angle was calculated for the results obtained from the trajectory of molecular dynamics simulation after the 10 nanoseconds (ns) duration. Totally four atoms were selected sequentially for both chains. The torsion angle of the main chain is the Methyl Terminal Torsion (MTT), which is defined by $\mathrm{MTT}_{\mathrm{i}}$ containing $\mathrm{H}_{\mathrm{i}+2}-\mathrm{C}_{\mathrm{i}-1}-\mathrm{C}_{\mathrm{i}}-\mathrm{C}_{\mathrm{i}+1}$ and $\mathrm{MTT}_{\mathrm{i}+1}$ containing $\mathrm{C}_{\mathrm{i}-1}-\mathrm{C}_{\mathrm{i}}-$ $\mathrm{C}_{i+1}-\mathrm{C}_{\mathrm{i}+2}$ (Figure 1). The torsion angle of the side chain is the Hydroxyl Terminal Torsion (HTT), that is defined by $\mathrm{HTT}_{i}$ containing $\mathrm{H}_{\mathrm{i}}-\mathrm{O}_{i}-\mathrm{C}_{i}-\mathrm{C}_{i+1}$ and $\mathrm{HTT}_{i+1}$ containing $\mathrm{O}_{\mathrm{i}}-\mathrm{C}_{\mathrm{i}}-\mathrm{C}_{\mathrm{i}+1}-\mathrm{C}_{\mathrm{i}+2}$ (Figure 2). 


\section{RESULTS AND DISCUSSION}

\section{Polymer builder and disordered system builder}

Molecular dynamics is the best method when compared to conventional methods to study and predict the polymer blends (Moolman et al., 2005). Initially, one chain of atactic PVA with a 1750 degree of polymerization was built.

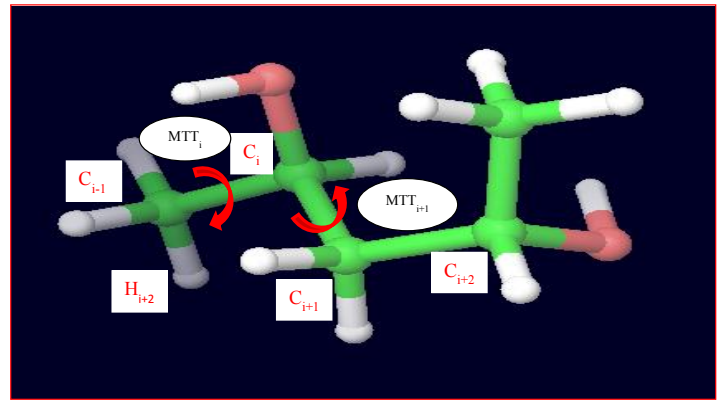

Figure 1.Mainchain Methyl Torsion Terminal (MTTi and $M T T i+1)$

A multicomponent system of hexanal and $\beta$ cyclodextrin packed in PVA polymer was built that was randomly distributed in a simulation box (Figure.3). The whole system was studied under periodic boundary conditions.

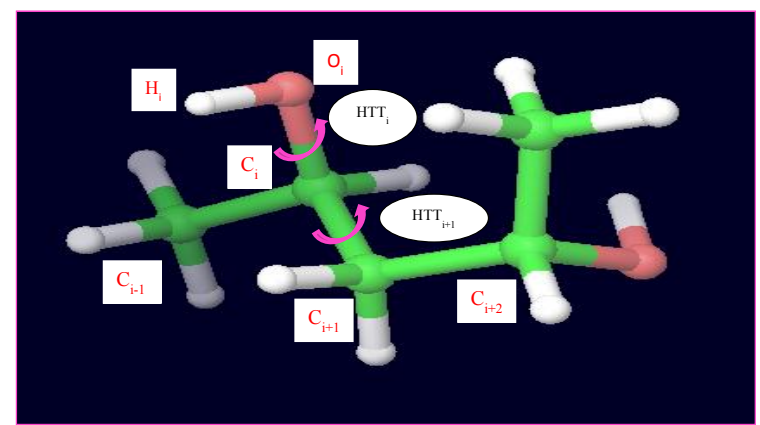

Figure 2. Side Chain Hydroxyl Torsion Terminal (HTTi and HTTi+1)

To conserve computational time, which enables the simulation to be performed using a relatively less number of monomers, another chain of PVA was built with 438 monomer units based on the mass percentage and used for subsequent simulations.

\section{Effect of Temperature and Humidity on the release of Hexanal using Molecular dynamics simulation}

MD simulation was carried out for the primary system at $27^{\circ} \mathrm{C}$ and $33^{\circ} \mathrm{C}$ for $5 \mathrm{~ns}$ and $10 \mathrm{~ns}$, respectively, with relative humidity ranging from $50 \%$ to $95 \%$, using Desmond software. The conformational changes were monitored using trajectory data obtained during the simulation. Results were obtained by the MD simulation. The trajectory result of $27^{\circ} \mathrm{C}$ and $33^{\circ} \mathrm{C}$ was considered a system I and system II, respectively. A PVA- $\beta$

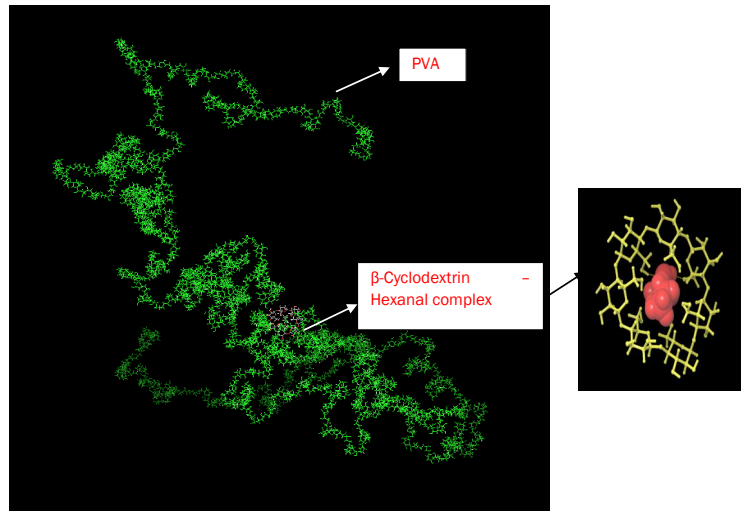

Figure 3.A multicomponent system of $\beta$ cyclodextrin and hexanal packed in PVA polymer was built that was randomly distributed in a simulation box. The green color matrix indicates the PVA polymer chain, in which the $\beta$ cyclodextrinHexanal complex has been entrapped. It has been magnified in the right side image where the yellow matrix indicates $\beta$ cyclodextrin and the red color compound is the entrapped hexanal

cyclodextrin-hexanal complex build for $50 \%$ relative humidity is presented in (Figure 4).

\section{Simulation analysis}

The movement of hexanal, their release, and the potential energy were calculated and plotted using simulation quality analysis and simulation event analysis. The movement of hexanal release and energy of the whole system was plotted for 5000 ps and 10000 ps for the system I and II, respectively.



Figure 4. A disordered system of PVA$\beta$-Cyclodextrin- hexanal complex- Green: PVA; Blue: $\beta$-Cyclodextrin; Red: Hexanal; Red dot: Water molecules 
Figure 5. Effect of Temperature and Humidity on the release of Hexanal

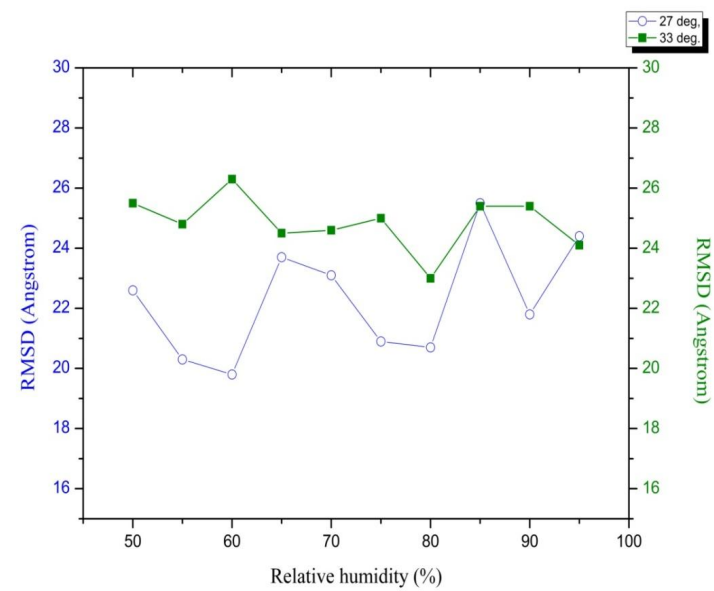

Simulation event analysis: Movement of hexanal release

The movement of hexanal release was analyzed through the MD simulation trajectory for systems I and II incorporated with water molecules corresponding to $50 \%$ relative humidity to $95 \%$ relative humidity at $27^{\circ} \mathrm{C}$ and $33^{\circ} \mathrm{C}$ for 5000 ps and 10000 ps, respectively. The values corresponding to the movement of hexanal from the nanofiber composite is given (Table 1 ).

Table 1. Movement of hexanal release at $27{ }^{\circ} \mathrm{C}$ $\& 33^{\circ} \mathrm{C}$

\begin{tabular}{|c|c|c|c|c|}
\hline $\begin{array}{l}\text { Relative Humidity } \\
\text { (\%) }\end{array}$ & @ 27 & $C(\AA ̊)$ & @ 33 & $C(\AA ̊)$ \\
\hline 50 & & 22.6 & & 25.5 \\
\hline 55 & & 20.3 & & 24.8 \\
\hline 60 & & 19.8 & & 26.3 \\
\hline 65 & & 23.7 & & 24.5 \\
\hline 70 & & 23.1 & & 24.6 \\
\hline 75 & & 20.9 & & 25 \\
\hline 80 & & 20.7 & & 23 \\
\hline 85 & & 25.5 & & 25.4 \\
\hline 90 & & 21.8 & & 25.4 \\
\hline 95 & & 24.4 & & 24.1 \\
\hline
\end{tabular}

Among the analysis of the MD simulation carried out for 5 ns at $27^{\circ} \mathrm{C}$, the minimum movement of hexanal release occurred when the relative humidity was at $60 \%$ and the maximum movement was observed when the relative humidity was at $85 \%$. The movement of hexanal release values from the MD trajectory frame with respect to the initial structure of hexanal lies at around $19.8(\AA)$ at $60 \%$ relative humidity and $25.5(\AA)$ at $85 \%$ relative humidity. The relative humidity triggers the release of volatile compounds (Ayala-Zavala et al., 2008). However, a slow release of the compound was observed at low relative humidity.

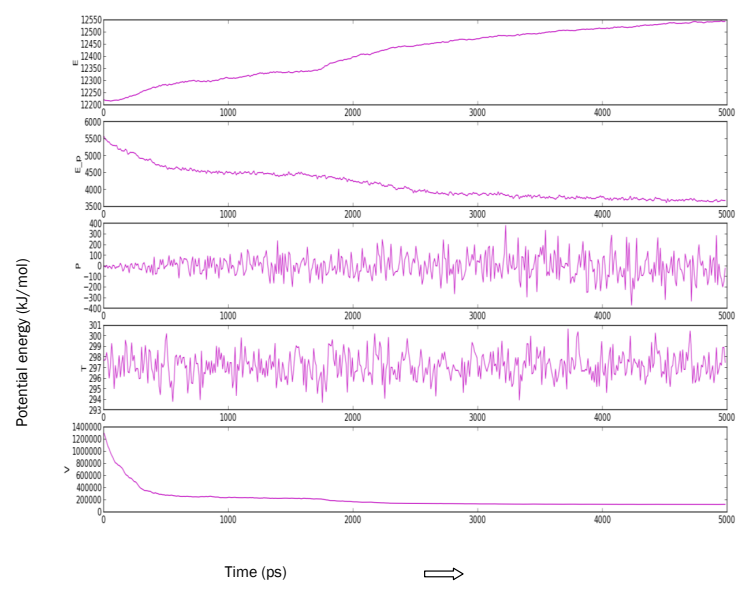

Figure 6. The energy trajectory of the PVA- $\beta$ cyclodextrin- Hexanal

The movement of hexanal release plot made for the PVA- $\beta$ cyclodextrin- hexanal complex at $27^{\circ} \mathrm{C}$ shows a little change in the initial position and revealed that the complex was stable throughout the simulation time of $5 \mathrm{~ns}$. It is obvious that at lower or ambient room temperature, the release of hexanal from the PVA- $\beta$ cyclodextrin composite is triggered by the presence of high relative humidity in the surrounding environment.

Table 2. Average potential energy (kJ/mol)

\begin{tabular}{ccc}
\hline $\begin{array}{c}\text { Relative } \\
\text { Humidity } \\
(\%)\end{array}$ & $\begin{array}{c}\text { Average } \\
\text { Potential } \\
\text { Energy (kJ/ } \\
\text { mol) at } 27^{\circ} \mathrm{C}\end{array}$ & $\begin{array}{c}\text { Average Potential } \\
\text { Energy (kJ/mol) at } \\
33^{\circ} \mathrm{C}\end{array}$ \\
\hline 50 & 14608.9091304 & 14909.8939956 \\
55 & 14418.7823556 & 14787.3044916 \\
60 & 14435.5128084 & 14704.858026 \\
65 & 14435.0773812 & 14776.4020644 \\
70 & 14362.8341472 & 14541.991506 \\
75 & 14364.764262 & 14608.9091304 \\
80 & 14398.0535088 & 14751.0677376 \\
85 & 14221.889712 & 14608.9091304 \\
90 & 14222.9657196 & 14608.9091304 \\
95 & 14256.2382192 & 14608.9091304 \\
\hline
\end{tabular}

This may be due to the high retention capacity of $\beta$ cyclodextrin that is able to hold on hexanal for a longer period of time. When there is a prevalence of lower relative humidity the release of hexanal from the composite is retarded to some extent. Similarly, when the humidity level was increased, the release of volatile I-menthol blended in gum arabic and modified starch was also increased (Del Toro-Sánchez et al., 2010). 

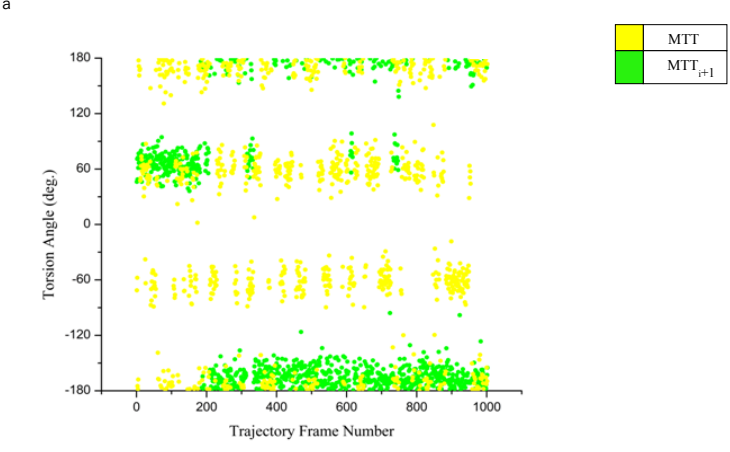

b

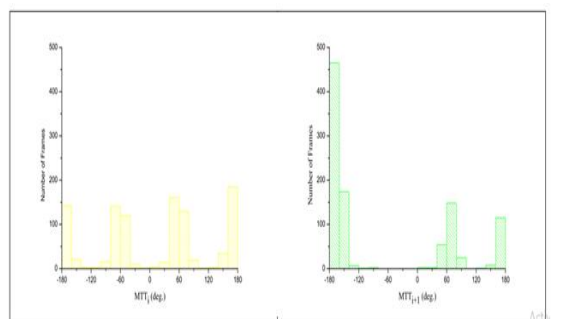

Figure 7. Torsion angles of main chain atoms of PVA (MTTi and MTTi+1)

The movement of hexanal release values of the MD trajectory frame with respect to the initial structure of hexanal lies at around $23(\AA)$ at 80 $\%$ relative humidity and $26.3(\AA)$ at $60 \%$ relative humidity. It reveals the change of the initial position of hexanal. From this result, it shows that when the temperature is increased, the hexanal release from the PVA- $\beta$ cyclodextrin composite is induced when there is a low relative humidity in the environment. The water molecules got destructured when there is a high temperature (Chiessi et al., 2005), and there are changes in the polymer conformation. This confirms our data that at a high temperature of $33^{\circ} \mathrm{C}$, water molecules get destructured rapidly, and due to the polymer chain conformation, hexanal is released quickly at low relative humidity level. In the presence of higher temperatures, the water molecules are released from the composite rapidly from the complex. PVA nanofibers were promising materials for the volatile entrapment, and incorporation of $\beta$ cyclodextrin helped in the encapsulation of a higher amount of volatiles (Aytac et al., 2014). The relevant graph for the movement of hexanal release from $50 \%-95 \%$ relative humidity at both $27^{\circ} \mathrm{C}$ and $33^{\circ} \mathrm{C}$ are presented in Figure.5.

\section{Simulation quality analysis: Energy of the nanofiber composite}

The energy of the PVA- $\beta$ cyclodextrin- the hexanalnano-fiber complex was analyzed (Figure.6). The energy scheme was plotted for the trajectory data obtained for the MD simulation result of the system I incorporated with water molecules corresponding to $50 \%$ relative humidity to $95 \%$ relative humidity at $27^{\circ} \mathrm{C}$ for 5000 ps and system Il at $33^{\circ} \mathrm{C}$ for $10000 \mathrm{ps}$. The Energy plot explains that the PVA- $\beta$ cyclodextrin- Hexanal nanofiber composite with water molecules were stable throughout every $5 \mathrm{~ns}$ and $10 \mathrm{~ns}$ simulation run at both $27^{\circ} \mathrm{C}$ and $33^{\circ} \mathrm{C}$. The average potential energy was calculated for the data from $50 \%$ - $95 \%$ relative humidity at both the temperatures (Table 2).
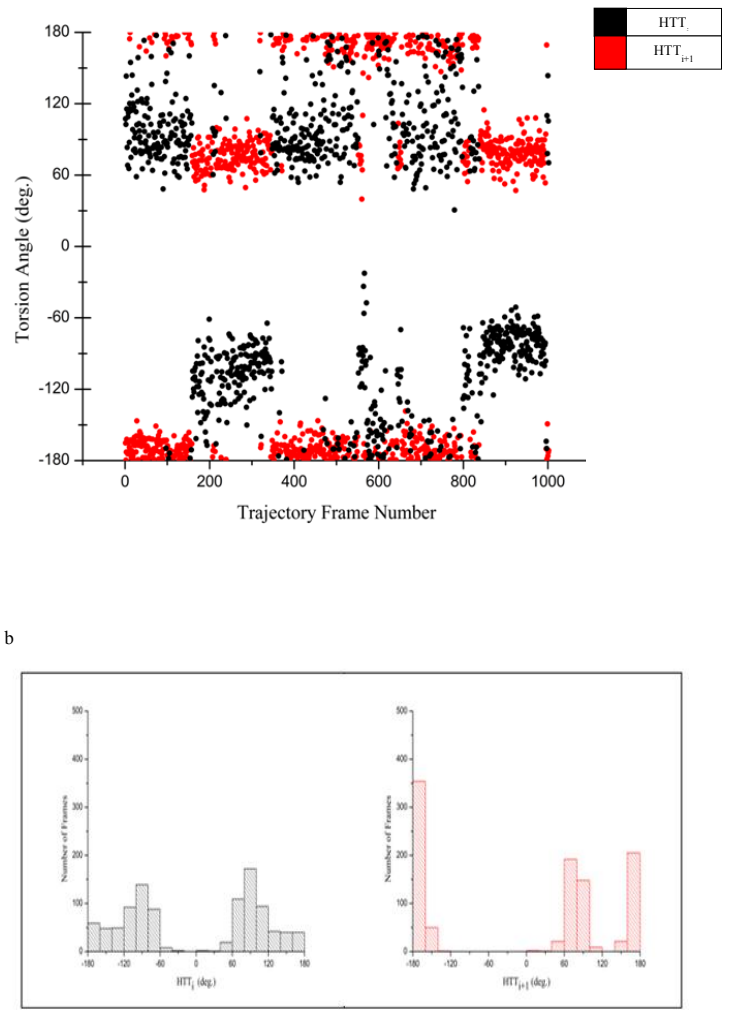

Figure 8. Torsion angles of side chain atoms of PVA (HTTi and HTTi+1)

The energy calculation done in simulation quality analysis revealed that at $27^{\circ} \mathrm{C}$ with $60 \%$ relative humidity, the total energy was $42703.182864 \mathrm{~kJ} /$ mol, potential energy was $14435.5128084 \mathrm{~kJ} /$ mol with 297.170 temperature $(K)$ and the volume was $116808.775\left(\AA^{3}\right)$, and the total energy was $42636.6839196 \mathrm{~kJ} / \mathrm{mol}$, potential energy was $14221.889712 \mathrm{~kJ} / \mathrm{mol}$ with 297.000 temperature (K), and the volume was $116881.779\left(\AA^{3}\right)$ with $85 \%$ relative humidity. For the energy calculation done at $33^{\circ} \mathrm{C}$ with $60 \%$ relative humidity, the total energy was $43535.0037276 \mathrm{~kJ} / \mathrm{mol}$, potential energy was $14704.858026 \mathrm{~kJ} / \mathrm{mol}$ with 303.083 temperature $(\mathrm{K})$, and the volume was $114292.746\left(\AA^{3}\right)$ and the total energy was $43714.0396692 \mathrm{~kJ} / \mathrm{mol}$, potential energy was $14751.0677376 \mathrm{~kJ} / \mathrm{mol}$ with 303.127 temperature $(\mathrm{K})$, and the volume was 118121.917 $\left(\AA^{3}\right)$ with $80 \%$ relative humidity. Cyclodextrin inclusion complex along with PVA can improve the stability and durability of vanillin (Kayaci and Uyar, 2012). The energy plot reveals that the energy of the whole 
PVA- $\beta$ cyclodextrin- hexanalnano-fiber composite was relatively stable throughout the simulation in 5 ns and 10 ns simulation run done at $27^{\circ} \mathrm{C}$ and $33^{\circ} \mathrm{C}$ with relative humidity $50 \%$ to $95 \%$. Nevertheless, potential energy is the responsible component for structural stability, which was equilibrated well during the simulation. When the guest molecules were introduced, the total energy-reduced enabling the complexation of volatile organic compound and cyclodextrin(Celebioglu et al., 2016).

\section{The motion of the PVA backbone chain}

The torsional angle conformers of the PVA chain were studied by the analysis of the main chain termed as Methyl Terminal Torsion (MTT) (Figure.7 a\&b) and side-chain termed as Hydroxyl Terminal Torsion (HTT) (Figure.8 a\&b). It is evident that the torsion angles of the PVA main chain showed a preferable transition in the range of $+180^{\circ}$ and $-180^{\circ},+50^{\circ}$ to $+70^{\circ}$, and $-50^{\circ}$ to $-70^{\circ}$ in $\mathrm{MTT}$. The $\mathrm{MTT}_{i+1}$ torsion angle of the PVA side chain showed a preferable transition in the range of $+180^{\circ},-180^{\circ}$, and $+60^{\circ}$ to $+70^{\circ}$. The torsion angle of the main chain of PVA preferred to be in $+90^{\circ},+180^{\circ},-90^{\circ}$, and $-180^{\circ}$ (De La Rosa et al., 2002). The HTT.torsion angles of the PVA side chain showed a preferable transition in the range of $+60^{\circ}$ to $+120^{\circ}$ and $-60^{\circ}$ to $-120^{\circ}$. The $\mathrm{HTT}_{\mathrm{i}+1}$ torsion angle of the PVA side chain showed a preferable transition in the range of $+60^{\circ}$ to $+100^{\circ},+180^{\circ}$, and $-180^{\circ}$. The preferable angles for side chain to be in $+40^{\circ},-160^{\circ},-180^{\circ}$ (De La Rosa et al., 2002). PVA dihedral angle is to be around $68^{\circ}$, $290^{\circ}$ and $179^{\circ}$. It was proved that in the main chain torsional angle, conformer was predominant, and PVA adopted gauche conformation, and the trans conformation was predominant in the PVA backbone (Merat et al., 2013).

\section{CONCLUSION}

Molecular dynamics simulation has been employed to study the release of hexanal from polyvinyl alcohol- $\beta$ cyclodextrin- hexanal complex. We have investigated the release and retention behavior of hexanal from the complex composite with the relative humidity range of $50 \%-95 \%$ at $27^{\circ} \mathrm{C}$ $(300 \mathrm{~K})$ and $33^{\circ} \mathrm{C}(303 \mathrm{~K})$ and new, complementary information were presented in this work. Here, the present simulation study focussed on building a simplified model to describe the complexation of polyvinyl alcohol- $\beta$ cyclodextrin- hexanal, which provides a close resemblance of their dynamic behavior in terms of root mean square deviation (RMSD), energy determination and conformational changes through determining the torsion angles. The effect of relative humidity on the Polyvinyl alcohol- $\beta$ cyclodextrin- hexanal for the release of hexanal at room or low temperature indicates the need for high relative humidity for a sustainable release of hexanal. At the same time, at high temperatures, the release of hexanal is triggered rapidly by the water molecules from the polymer and $\beta$ cyclodextrin complex. In particular, the generated model and the analysis have shown the importance of the relative humidity and temperature on the release of the volatile, hexanal from the complex. Further, these results help in the manipulation of the hexanal release by controlling the relative humidity and temperature in the storage condition for enhancing the shelf-life of perishables. The data demonstrated that hexanal vapor release from the nanocomposite of electrospun nanofibers composite is distinct between two temperature and $\mathrm{RH}$ regimes coincides with the fruit storage in the off-season and regular season mangoes. The kinetics of hexanal vapor release matched and well-fit with molecular modeling tools and techniques. Based on the above results, it is apparent that molecular dynamics have a great potential in predicting the complexation of polymer with the inclusion complex of $\beta$ cyclodextrin and hexanal and its release, where it is difficult to determine through experimental analysis by the conventional method.

\section{Funding and Acknowledgment}

This work was supported by the Canadian International Development Agency (CIDA) and the International Development Research Centre (IDRC) through the CIFSRF project.

\section{Consent for publication}

All the authors agreed to publish the content.

\section{Competing interests}

There was no conflict of interest in the publication of this content

\section{REFERENCES}

Ali, N. 2003. Post Harvest Technology for Employment Generation in Rural Sector Of India. Paper presented at the Regional Seminar on Post-Harvest Technology for Major Crops 3-5 November 2003.

Anusuya, P., Nagaraj, R., Janavi, G.J., Subramanian, K. S., Paliyath, G., and Subramanian, J. 2016. Preharvest sprays of hexanal formulation for extending retention and shelf-life of mango (Mangifera indica L.) fruits. Scientia Horticulturae, 211: 231-240.

Ayala-Zavala, J., Del-Toro-Sánchez, L., Alvarez-Parrilla, E., and González-Aguilar, G. 2008. High relative humidity in-package of fresh-cut fruits and vegetables: advantage or disadvantage considering microbiological problems and antimicrobial delivering systems? Journal of Food Science, 73(4): R41-R47.

Aytac, Z., Dogan, S.Y., Tekinay, T., and Uyar, T. 2014. Release and antibacterial activity of allyl isothiocyanate/-cyclodextrin complex encapsulated in electrospun nanofibers. Colloids and Surfaces B: Biointerfaces, 120: 125-131. 
Celebioglu, A., Sen, H.S., Durgun, E., and Uyar, T. 2016. Molecular entrapment of volatile organic compounds (VOCs) by electrospun cyclodextrin nanofibers. Chemosphere, 144: 736-744.

Chiessi, E., Cavalieri, F., and Paradossi, G. 2005. Supercooled water in PVA matrixes. II. A molecular dynamics simulation study and comparison with QENS results. The Journal of Physical Chemistry $B, 109$ (16): 8091-8096.

De La Rosa, A., Heux, L., Cavaillé, J.-Y., and Mazeau, K. 2002. Molecular modeling of the mobility of poly (allyl alcohol), PAA, and poly (vinyl alcohol), PVA. Polymer, 43(21): 5665-5677.

Del Toro-Sánchez, C., Ayala-Zavala, J., Machi, L., Santacruz, H., Villegas-Ochoa, M., Alvarez-Parrilla, E., and González-Aguilar, G. 2010. Controlled release of antifungal volatiles of thyme essential oil from -cyclodextrin capsules. Journal of inclusion phenomena and macrocyclic chemistry, 67(3-4): 431-441.

Greiner, A., and Wendorff, J.H.J. a. C.I.E. 2007. Electrospinning: a fascinating method for the preparation of ultrathin fibers.46(30): 5670-5703.

Hodges, R.J., Buzby, J.C., and Bennett, B. 2011. Postharvest losses and waste in developed and less developed countries: opportunities to improve resource use. The Journal of Agricultural Science, 149(S1): 37-45.

Iram, S., and Ahmad, H. 2013. Major post harvest diseases of Mango and their management. International Journal of Agronomy and Plant Production, 4(12): 3470-3484.

Jincy, M., Djanaguiraman, M., Jeyakumar, P., Subramanian, K., Jayasankar, S., and Paliyath, G. 2017. Inhibition of phospholipase D enzyme activity through hexanal leads to delayed mango (Mangifera indica L.) fruit ripening through changes in oxidants and antioxidant enzymes activity. Scientia Horticulturae, 218: 316-325.

Kader, A.A. 2003. A perspective on postharvest horticulture (1978-2003). Hort Science, 38(5): 1004-1008.

Kayaci, F., Sen, H.S., Durgun, E., and Uyar, T. J. F. R. I. 2014. Functional electrospun polymeric nanofibers incorporating geraniol-cyclodextrin inclusion complexes: High thermal stability and enhanced durability of geraniol.62: 424-431.
Kayaci, F., and Uyar, T. 2012. Encapsulation of vanillin/ cyclodextrin inclusion complex in electrospun polyvinyl alcohol (PVA) nanowebs: prolonged shelflife and high temperature stability of vanillin. Food chemistry, 133(3): 641-649.

Li, D., and Xia, Y.J. a. M. 2004. Electrospinning of nanofibers: reinventing the wheel?, 16(14): 1151-1170.

Lurie, S., and Paliyath, G. 2009. Enhancing Postharvest Shelf Life and Quality in Horticultural Commodities. Postharvest Biology and Technology of Fruits, Vegetables, and Flowers, 139.

Maheshwar, C., and Chanakwa, T. 2006. Postharvest losses due to gaps in cold chain in India-a solution. Paper presented at the IV International Conference on Managing Quality in Chains-The Integrated View on Fruits and Vegetables Quality 712.

Merat, K., Chaodamrongsakul, J., Tanthanuch, W., and Vao-Soongnern, V. 2013. Atomistic solvation structure of calcium ion in poly (vinyl alcohol) as studied by molecular dynamics simulation and X-ray absorption spectroscopy. Journal of non-crystalline solids, 371: 47-52.

Moolman, F., Meunier, M., Labuschagne, P. W., and Truter, P.-A. 2005. Compatibility of polyvinyl alcohol and poly (methyl vinyl ether-co-maleic acid) blends estimated by molecular dynamics. Polymer, 46(16): 6192-6200.

Paliyath, G., Pinhero, R.G., Yada, R.Y., and Murr, D. P. 1999. Effect of processing conditions on phospholipase D activity of corn kernel subcellular fractions. Journal of agricultural and food chemistry, 47(7): 2579-2588.

Radosinski, L., and Labus, K. 2017. Molecular modeling studies of structural properties of polyvinyl alcohol: a comparative study using INTERFACE force field. Journal of molecular modeling, 23(11): 305.

Reis, E.F.D., Campos, F.S., Lage, A.P., Leite, R.C., Heneine, L.G., Vasconcelos, W.L., Mansur, H.S. 2006. Synthesis and characterization of poly (vinyl alcohol) hydrogels and hybrids for rMPB70 protein adsorption. Materials Research, 9(2): 185-191.

Rolle, R.S. 2006. Improving postharvest management and marketing in the Asia-Pacific region: issues and challenges. Postharvest management of fruit and vegetables in the Asia-Pacific region, 1(1): 23-31.

Wu, C. 2010. Cooperative behavior of poly (vinyl alcohol) and water as revealed by molecular dynamics simulations. Polymer, 51(19): 4452-4460. 